http://dx.doi.org/10.1590/1678-4162-8975

Arq. Bras. Med. Vet. Zootec., v.69, n.2, p.497-504, 2017

\title{
Características produtivas, carcaça, cortes e resposta imune humoral de frangos de corte alimentados com diferentes fontes de óleo e vitamina $\mathbf{E}$
}

[Productive and humoral immune response of broilers fed with different sources of oil and vitamin E]

\author{
J.A. Barbosa Filho ${ }^{1}$, A.L. Soares ${ }^{1}$, M.C. Santos ${ }^{2}$, E.J. Venancio ${ }^{1}$, M. Almeida ${ }^{1}$, \\ F.R. Bueno ${ }^{1}$, M. Shimokomaki ${ }^{1}$, A. Oba $^{1}$ \\ ${ }^{1}$ Universidade Estadual de Londrina - UEL - Londrina, PR \\ ${ }^{2}$ Universidade Estadual de Campinas - Unicamp - Campinas, SP
}

\begin{abstract}
RESUMO
A adição de óleos na dieta de frangos de corte proporciona muitas vantagens, visto que, dependendo do perfil de ácidos graxos, pode melhorar o desempenho e atuar como estimulante do sistema imune. Assim, este estudo teve como objetivo avaliar as características produtivas, o rendimento de carcaça, os cortes e a resposta imune humoral de frangos de corte alimentados com diferentes fontes de óleos e vitamina E. Foram utilizados 312 pintainhos de corte machos da linhagem Cobb com um dia de idade, distribuídos em delineamento inteiramente ao acaso, com oito repetições compostas de 13 aves por parcela experimental. Os tratamentos experimentais consistiram em óleo de soja, óleo de canola e óleo de canola mais adição de vitamina E. As variáveis analisadas foram ganho de peso, consumo de ração, conversão alimentar, rendimento de carcaça, cortes comerciais e resposta imune humoral. Os resultados obtidos mostram que houve diferença significativa no desempenho somente na fase pré-inicial, quando as aves que receberam o tratamento com óleo de canola e vitamina E apresentaram piores ganhos de peso. Não foram observadas diferenças significativas para as outras variáveis analisadas. Conclui-se que a utilização de diferentes fontes lipídicas associadas ou não à vitamina $\mathrm{E}$ não afeta as características produtivas de carcaça, cortes e resposta imune humoral em frangos de corte em relação ao uso de óleo de soja.
\end{abstract}

Palavras-chave: aves, óleo de canola, óleo de soja, tocoferol

\begin{abstract}
Oil inclusion in poultry diets provides many advantages and according to the fatty acid profile it is possible to achieve performance improvement as well as immune system stimulation. Thus, the study aimed to evaluate productive performance, carcass and cuts yields and also the humoral immune response of broilers consuming diets formulated with different oil sources and vitamin E. A total of 312 one-day old male Cobb was distributed, in a completely randomized design, in three treatments with eight replications of 13 birds. The experimental treatments were the diets that had different oil source as follows: soybean oil, canola oil and canola oils with vitamin E. The analyzed parameters were weight gain, feed intake, feed conversion ratio, carcass and cut yields and humoral immune response. For the treatment with canola oil and vitamin $E$ a reduction on weight gain during the pre-starter stage was observed. For the other evaluated parameters, no significant differences were observed. In conclusion, the use of canola oil or canola oil with added vitamin E does not affect the productive performance, carcass and cut yields and humoral immune response in broiler chicken in relation soybean oil use.
\end{abstract}

Keywords: poultry, canola oil, soybean oil, tocopherol

Recebido em 24 de agosto de 2016

Aceito em 4 de outubro de 2016

E-mail: joaoabfzootecnista@gmail.com 


\section{INTRODUÇÃO}

A evolução da avicultura no Brasil encontra-se pautada nos grandes avanços observados nas áreas de genética, nutrição, sanidade, ambiência e manejo (Carvalho et al., 2015). Para suprir a demanda desse produto, adotaram-se estratégias a fim de se produzirem frangos com um crescimento mais rápido e com menor tempo de abate, o que resultou em problemas na saúde dos animais. Com isso, muitos ingredientes vêm sendo utilizados e estudados na nutrição de aves com a finalidade de melhorar o sistema imunológico e o desempenho desses animais (Klasing, 1998; Kidd, 2004).

Dentre esses ingredientes, encontram-se os óleos, que são empregados para elevar a concentração energética das dietas (Fascina, 2007), melhorar as características de desempenho (Baião e Lara, 2005) e atuar na resposta imune humoral (Pinto et al., 2014). Outro nutriente relevante para o desenvolvimento das aves é a vitamina $\mathrm{E}$, reconhecida por ser essencial para um conjunto de atividades do organismo, dentre elas a integridade reprodutiva, muscular, circulatória, nervosa e imunológica dos animais (Pompeu et al., 2015).

Existe um grande número de pesquisas direcionadas a investigar os efeitos da ingestão de ácido graxos poli-insaturados em associação com a vitamina E sobre a qualidade da carne de frango (Cortinas et al., 2005; Santos, 2014), no entanto há poucos trabalhos que avaliam a imunologia (Ahmed et al., 2013).

Diante do exposto, o presente estudo teve como objetivo avaliar o desempenho, as características de carcaça, os cortes comerciais e a resposta imune humoral de frangos de corte alimentados com rações contendo óleos de diferentes fontes combinadas com vitamina $\mathrm{E}$.

\section{MATERIAL E MÉTODOS}

O experimento foi realizado na Unidade de Pesquisa em Nutrição de Aves da Universidade Estadual de Londrina, sendo aprovado pela Comissão de Ética no Uso de Animais, com o registro de processo 27698.2012.58.

Foram utilizados 312 pintainhos de corte, machos, da linhagem Cobb, com um dia de idade. As aves foram criadas de acordo com o manejo comercial, com água e alimento ad libitum, durante todo o período experimental de 42 dias, o qual foi dividido em quatro fases: préinicial (um a sete dias de idade), inicial (oito a 21 dias de idade), crescimento (22 a 35 dias de idade) e terminação (36 a 42 dias de idade).

As rações experimentais atendiam as exigências mínimas preconizadas por Rostagno et al. (2011), sendo específicas para cada fase, inclusive o tipo de óleo e a inclusão de vitamina E, conforme as Tab. 1 e 2. Foi adotado um delineamento inteiramente ao acaso, com três tratamentos com oito repetições de 13 aves por parcela experimental. Os tratamentos experimentais foram óleo de soja, óleo de canola e óleo de canola mais vitamina $\mathrm{E}$.

Para a determinação do desempenho zootécnico das aves, foram avaliados o consumo de ração, o ganho de peso e a conversão alimentar.

Aos 42 dias de idade, duas aves que representavam o peso médio de cada parcela experimental foram submetidas a um período de oito horas de jejum alimentar, transportadas em veículo automotivo por um período de 30 minutos e, em seguida, descarregadas na plataforma de abate para pesagem individual de cada ave. Depois, as aves foram insensibilizadas eletricamente por meio do aparelho da marca Fluxo, modelo FX 2.0, no qual foram expostas por 10 segundos a 42 volts e $800 \mathrm{~Hz}$ (Contreras e Beraquet, 2001), sangradas, escaldadas, depenadas, evisceradas e submetidas aos cortes comerciais para a determinação do rendimento de carcaça e cortes.

A determinação do rendimento da carcaça foi realizada conforme a metodologia descrita por Mendes (2001), em que se considerou o peso da carcaça eviscerada (sem cabeça, pés e pescoço) em relação ao peso vivo de abate. Os cortes de peito, pernas (coxa + sobrecoxa), dorso e asas tiveram seus respectivos rendimentos determinados em relação ao peso da carcaça eviscerada.

Também foi pesada a gordura abdominal e, em seguida, determinada a porcentagem em relação ao peso da carcaça eviscerada. A gordura abdominal foi constituída pelo tecido adiposo presente desde a moela até o conteúdo existente ao redor da cloaca e bursa de Fabricius, conforme descrito por Smith (1993). 
Tabela 1. Composição percentual e valores nutricionais calculados das dietas experimentais nas fases préinicial e inicial de aves alimentadas com óleo de soja (S), óleo de canola (C) e óleo de canola mais vitamina $\mathrm{E}(\mathrm{CE})$

\begin{tabular}{|c|c|c|c|c|c|c|}
\hline \multirow{3}{*}{ Ingredientes (\%) } & \multicolumn{6}{|c|}{ Fases de produção } \\
\hline & \multicolumn{3}{|c|}{$1-7$ dias } & \multicolumn{3}{|c|}{$8-21$ dias } \\
\hline & $\mathrm{S}$ & $\mathrm{C}$ & $\mathrm{CE}$ & $\mathrm{S}$ & $\mathrm{C}$ & $\mathrm{CE}$ \\
\hline Milho grão & 54,68 & 54,68 & 54,68 & 57,13 & 57,14 & 57,14 \\
\hline Farelo de soja & 38,73 & 38,73 & 38,73 & 35,93 & 35,90 & 35,90 \\
\hline Óleo de soja & 2,34 & - & - & 3,22 & - & - \\
\hline Óleo de canola & - & 2,34 & 2,34 & - & 3,22 & 3,22 \\
\hline Fosfato bicálcico & 1,90 & 1,90 & 1,90 & 1,55 & 1,55 & 1,55 \\
\hline Calcário & 0,88 & 0,88 & 0,88 & 0,91 & 0,91 & 0,91 \\
\hline Sal comum & 0,50 & 0,50 & 0,50 & 0,48 & 0,48 & 0,48 \\
\hline DL-Metionina & 0,36 & 0,36 & 0,36 & 0,28 & 0,28 & 0,28 \\
\hline L-Lisina $\mathrm{HCl}$ & 0,29 & 0,29 & 0,29 & 0,23 & 0,25 & 0,25 \\
\hline L-treonina & 0,11 & 0,11 & 0,11 & 0,08 & 0,08 & 0,08 \\
\hline Suplemento mineral $^{1}$ & 0,15 & 0,15 & 0,15 & 0,13 & 0,13 & 0,13 \\
\hline Suplemento vitamínico ${ }^{2}$ & 0,06 & 0,06 & 0,06 & 0,06 & 0,06 & 0,06 \\
\hline Total $(\%)$ & 100,00 & 100,00 & 100,00 & 100,00 & 100,00 & 100,00 \\
\hline EM (kcal/kg) & 2960 & 2960 & 2960 & 3050 & 3050 & 3050 \\
\hline Proteína bruta (\%) & 22,40 & 22,40 & 22,40 & 21,20 & 21,20 & 21,20 \\
\hline Metionina dig. (\%) & 0,651 & 0,651 & 0,651 & 0,557 & 0,557 & 0,557 \\
\hline Met + Cis dig. (\%) & 0,953 & 0,953 & 0,953 & 0,846 & 0,846 & 0,846 \\
\hline Lis dig. (\%) & 1,324 & 1,324 & 1,324 & 1,217 & 1,225 & 1,225 \\
\hline Treonina dig (\%) & 0,861 & 0,861 & 0,861 & 0,791 & 0,791 & 0,791 \\
\hline Cálcio (\%) & 0,920 & 0,920 & 0,920 & 0,841 & 0,841 & 0,841 \\
\hline Fósforo disp. (\%) & 0,470 & 0,470 & 0,470 & 0,401 & 0,401 & 0,401 \\
\hline Vitamina E (mg.kg $\left.{ }^{-1}\right)$ & - & - & 150 & - & - & 150 \\
\hline $\begin{array}{l}{ }^{1} \text { Composição do suplemen } \\
0,39 \text { mg. } \\
{ }^{2} \text { Composição do suplemen } \\
3 \mathrm{mg} \text {; vit. } \mathrm{B}_{1}: 2,7 \mathrm{mg} \text {; vit. } \\
\text { ácido fólico: } 1,2 \mathrm{mg} \text {; biotin }\end{array}$ & $\begin{array}{l}\text { oor kg de } \\
\text { co por k }\end{array}$ & $\begin{array}{l}\text { luto: Fe: } \\
\text { produto: }\end{array}$ & $\begin{array}{l}\text { g; } \mathrm{Cu}: 24 \\
\text { A: } 15.00\end{array}$ & $\begin{array}{l}\mathrm{Mn}: 102 \\
\text { vit. } \mathrm{D}_{3}: 2\end{array}$ & $\begin{array}{l}\text { Zn: } 81 \mathrm{mg} \\
\text { UI; vit. }\end{array}$ & $\begin{array}{l}\text {,08mg; } \mathrm{S} \\
\text { JI; vit. K }\end{array}$ \\
\hline
\end{tabular}

A análise da resposta imune secundária foi realizada conforme descrito por Kreukniet et al. (1992) e El-Abasy et al. (2004), em que amostras do sangue periférico de dois animais por tratamento foram obtidas no $14^{\circ}$ dia do experimento e utilizadas como amostras préimunização. A seguir, oito animais de cada tratamento foram inoculados com $200 \mu \mathrm{L}$ de uma solução de hemácias de carneiro a 5\% em PBS $0,15 \mathrm{M} \mathrm{pH} 7,2$ pela via intramuscular no $21^{\circ}$ e $35^{\circ}$ dias do experimento. No $42^{\circ}$ dia do experimento, amostras do sangue periférico foram obtidas para obtenção de soro e posterior análise dos níveis de anticorpos anti-hemácias de carneiro.

Os níveis de anticorpos anti-hemácias de carneiro foram determinados por ELISA como descrito por Ladics (2007), com modificações. Inicialmente, placas de ELISA de fundo chato foram sensibilizadas com o extrato de proteína de hemácias de carneiro na concentração de $2500 \mathrm{ng} / \mathrm{mL}$, por $18 \mathrm{~h}$, a $4^{\circ} \mathrm{C}$. A seguir, as placas foram lavadas com PBS-Tween 20 a $0,05 \%$, e os sítios inespecíficos foram bloqueados com PBS-leite a 5\% por uma hora, em temperatura ambiente (TA). As placas foram lavadas novamente com PBSTween 20 a $0,05 \%$ por três vezes, e as amostras de soro diluído 1:100 foram adicionadas. Após uma hora em TA, as placas foram lavadas como descrito acima, e o conjugado anti-IgYperoxidase (BethylLaboratories, inc) nas diluições de 1:40000 foi adicionado e incubado durante uma hora em TA. As placas foram lavadas novamente com PBS-Tween 20 a $0,05 \%$ por três vezes. $\mathrm{O}$ substrato/cromógeno, $\mathrm{H}_{2} \mathrm{O}_{2}(\mathrm{~F}$. Maia, Cotia, SP, Brasil)/ TMBZ (Sigma, St. Louis, USA)/ tampão acetato de sódio a $0,1 \mathrm{M} \mathrm{pH}$ 5,0 , foi adicionado, e a reação interrompida com a adição de $\mathrm{H}_{2} \mathrm{SO}_{4}$ a $1 \mathrm{~N}$. A densidade óptica foi determinada em leitor multiskan Thermo Plate (TP-Reader, Rayto Life and Analytical Sciences Co. Ltd, Germany) a 450nm. 
Tabela 2. Composição percentual e valores nutricionais calculados das dietas experimentais nas fases crescimento e terminação de aves alimentadas com óleo de soja (S), óleo de canola (C) e óleo de canola mais vitamina $\mathrm{E}(\mathrm{CE})$

\begin{tabular}{|c|c|c|c|c|c|c|}
\hline \multirow{3}{*}{ Ingredientes (\%) } & \multicolumn{6}{|c|}{ Fases de produção } \\
\hline & \multicolumn{3}{|c|}{$22-35$ dias } & \multicolumn{3}{|c|}{$36-42$ dias } \\
\hline & $\mathrm{S}$ & $\mathrm{C}$ & $\mathrm{CE}$ & $\mathrm{S}$ & $\mathrm{C}$ & $\mathrm{CE}$ \\
\hline Milho grão & 60,19 & 60,20 & 60,20 & 64,53 & 64,53 & 64,53 \\
\hline Farelo de soja & 32,29 & 32,27 & 32,27 & 28,40 & 28,39 & 28,39 \\
\hline Óleo de soja & 4,11 & - & - & 4,01 & - & - \\
\hline Óleo de canola & - & 4,11 & 4,11 & - & 4,01 & 4,01 \\
\hline Fosfato bicálcico & 1,33 & 1,33 & 1,33 & 1,12 & 1,12 & 1,12 \\
\hline Calcário & 0,86 & 0,86 & 0,86 & 0,77 & 0,77 & 0,77 \\
\hline Sal comum & 0,45 & 0,45 & 0,45 & 0,44 & 0,44 & 0,44 \\
\hline DL-Metionina & 0,29 & 0,29 & 0,29 & 0,27 & 0,27 & 0,27 \\
\hline L-Lisina $\mathrm{HCl}$ & 0,24 & 0,25 & 0,25 & 0,26 & 0,27 & 0,27 \\
\hline L-treonina & 0,07 & 0,07 & 0,07 & 0,07 & 0,07 & 0,07 \\
\hline Suplemento mineral $^{1}$ & 0,12 & 0,12 & 0,12 & 0,09 & 0,09 & 0,09 \\
\hline Suplemento vitamínico ${ }^{2}$ & 0,05 & 0,05 & 0,05 & 0,04 & 0,04 & 0,04 \\
\hline Total (\%) & 100,00 & 100,00 & 100,00 & 100,00 & 100,00 & 100,00 \\
\hline EM (kcal/kg) & 3150 & 3150 & 3150 & 3200 & 3200 & 3200 \\
\hline Proteína bruta (\%) & 19,80 & 19,80 & 19,80 & 18,40 & 18,40 & 18,40 \\
\hline Metionina dig. (\%) & 0,554 & 0,554 & 0,554 & 0,518 & 0,519 & 0,519 \\
\hline Met + Cis dig. $(\%)$ & 0,826 & 0,826 & 0,826 & 0,774 & 0,774 & 0,774 \\
\hline Lis dig. (\%) & 1,131 & 1,137 & 1,137 & 1,060 & 1,063 & 1,063 \\
\hline Treonina dig (\%) & 0,735 & 0,735 & 0,735 & 0,689 & 0,689 & 0,689 \\
\hline Cálcio (\%) & 0,758 & 0,758 & 0,758 & 0,664 & 0,663 & 0,663 \\
\hline Fósforo disp. (\%) & 0,354 & 0,354 & 0,354 & 0,309 & 0,309 & 0,309 \\
\hline Vitamina E (mg.kg $\left.{ }^{-1}\right)$ & - & - & 150 & - & - & 150 \\
\hline \multicolumn{7}{|c|}{ 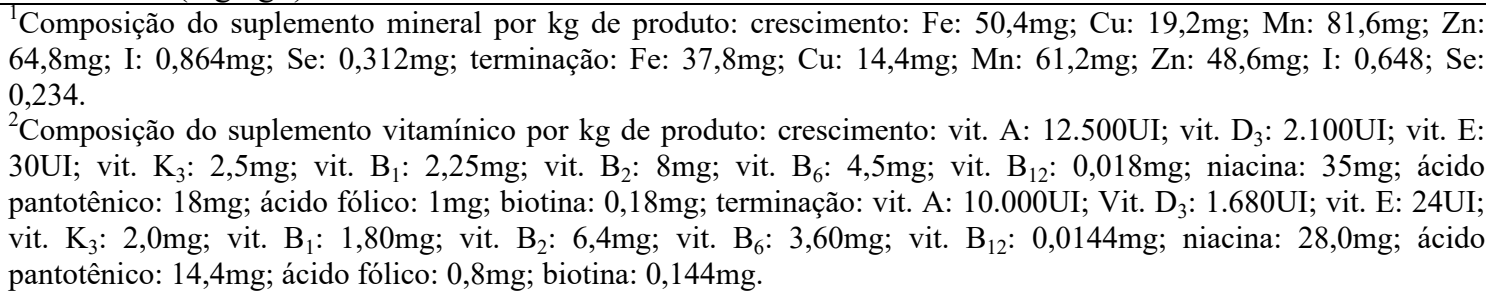 } \\
\hline
\end{tabular}

As análises estatísticas foram realizadas por meio de análise de variância e comparações entre médias, utilizando-se o teste de Tukey ao nível de $5 \%$ de significância, mediante o uso do software estatístico R. Para a análise da resposta imune humoral, os dados foram transformados utilizando-se a raiz quadrada.

\section{RESULTADOS E DISCUSSÃO}

Os resultados de desempenho zootécnico de frangos de corte alimentados com óleo de soja, óleo de canola e óleo de canola associado com vitamina $\mathrm{E}$ (Tab. 3) mostram que houve efeito significativo no período de um a sete dias de idade, quando as aves que se alimentaram de óleo de soja apresentaram maior ganho de peso $(\mathrm{P}<0,05)$ em relação às aves alimentadas com óleo de canola + vitamina $\mathrm{E}$, enquanto nos demais períodos de produção não houve diferença.

Resultados semelhantes foram obtidos por Mollaei et al. (2015), que, ao substituírem o óleo de soja por óleo de canola com níveis de $2 \%$ e $4 \%$, mais a inclusão de $150 \mathrm{mg}$ de vitamina $\mathrm{E} / \mathrm{kg}$ de ração em frangos de corte, observaram que a combinação de $4 \%$ de óleo de canola + vitamina E resultou em menor ganho de peso das aves. 
Tabela 3. Ganho de peso (GP), consumo de ração (CR) e conversão alimentar (CA) de frangos de corte machos alimentados com óleo de soja, óleo de canola e óleo de canola + vitamina E.

\begin{tabular}{|c|c|c|c|c|c|}
\hline \multirow[b]{2}{*}{ Variáveis } & \multicolumn{3}{|c|}{ Tratamentos } & \multirow[b]{2}{*}{ CV (\%) } & \multirow[b]{2}{*}{ P valo } \\
\hline & Óleo de soja & Óleo de canola & $\begin{array}{c}\text { Óleo de canola + } \\
\text { vit. E }\end{array}$ & & \\
\hline \multicolumn{6}{|c|}{$1-7$ dias } \\
\hline CR (g) & $168 \mathrm{a}$ & $165 \mathrm{a}$ & $161 \mathrm{a}$ & 2,93 & 0,054 \\
\hline GP (g) & $137 \mathrm{a}$ & $135 \mathrm{ab}$ & $128 \mathrm{~b}$ & 4,55 & 0,036 \\
\hline $\mathrm{CA}$ & $1,23 \mathrm{a}$ & $1,22 \mathrm{a}$ & $1,26 \mathrm{a}$ & 5,50 & 0,511 \\
\hline \multicolumn{6}{|c|}{$1-21$ dias } \\
\hline CR (g) & $1280 \mathrm{a}$ & 1261a & $1243 a$ & 2,89 & 0,186 \\
\hline GP (g) & $897 a$ & $891 \mathrm{a}$ & $862 \mathrm{a}$ & 3,41 & 0,097 \\
\hline $\mathrm{CA}$ & $1,43 \mathrm{a}$ & $1,42 \mathrm{a}$ & $1,44 \mathrm{a}$ & 1,76 & 0,347 \\
\hline \multicolumn{6}{|c|}{$1-35$ dias } \\
\hline CR (g) & $3537 \mathrm{a}$ & $3532 a$ & $3435 a$ & 2,97 & 0,150 \\
\hline GP (g) & $2270 \mathrm{a}$ & $2256 a$ & $2181 \mathrm{a}$ & 3,31 & 0,084 \\
\hline CA & $1,56 \mathrm{a}$ & $1,56 \mathrm{a}$ & $1,57 \mathrm{a}$ & 1,26 & 0,422 \\
\hline \multicolumn{6}{|c|}{$1-42$ dias } \\
\hline CR (g) & $4867 \mathrm{a}$ & $4833 a$ & $4738 \mathrm{a}$ & 3,17 & 0,289 \\
\hline GP (g) & $2956 a$ & $2950 \mathrm{a}$ & $2874 a$ & 2,60 & 0,116 \\
\hline $\mathrm{CA}$ & $1,66 \mathrm{a}$ & $1,66 \mathrm{a}$ & $1,65 \mathrm{a}$ & 3,25 & 0,964 \\
\hline
\end{tabular}

Médias seguidas de letras diferentes, na mesma linha, diferem entre si pelo teste de Tukey $(\mathrm{P}<0,05)$.

O menor ganho de peso para o uso de óleo de canola mais a suplementação de vitamina $\mathrm{E}$ somente na fase pré-inicial pode ter sido em razão de que, nesta fase, as aves são mais sensíveis. Além disso, segundo Leeson e Summers (2001), o óleo de canola possui ácido erúcico, que inibe o consumo de ração, comprometendo o ganho de peso, enquanto a vitamina $\mathrm{E}$ em excesso, de acordo com Nobakht et al. (2012), pode causar prejuízos no desempenho das aves, pois essa vitamina pode interagir com outros nutrientes, como a vitamina $\mathrm{A}$, reduzindo a quantidade desta $\mathrm{e}$, consequentemente, a capacidade da tireoide de captar iodo e sintetizar os hormônios T3 e T4, reduzindo, assim, o desempenho animal.
Ainda, esses resultados inferiores nesta fase podem ser também em razão do menor valor de energia metabolizável aparente corrigida (EMAn), visto que Junqueira et al. (2005), ao avaliarem diferentes fontes lipídicas em frangos, encontraram valor de EMAn para o óleo de canola de $8.129 \mathrm{kcal} / \mathrm{kg}$, bem inferior ao obtido para o óleo de soja $(9.201 \mathrm{kcal} / \mathrm{kg})$, cujos coeficientes de metabolização da energia bruta foram de 84,42 e $93,25 \%$, respectivamente. Os autores atribuíram esse fato à presença de altos níveis de ácido erúcico (acima de $2 \mathrm{mg} / \mathrm{g}$ ). Resultados semelhantes também foram relatados por Sim et al. (1985), que observaram que o ácido erúcico prejudicou a digestibilidade dos lipídios totais da ração e a digestibilidade individual de seus ácidos graxos.

Tabela 4. Rendimento de carcaça (RC), rendimento de peito (RP), rendimento de pernas (RPE), rendimento de dorso (RD), rendimento de asas (RA) e rendimento de gordura abdominal (RGA) de frangos de corte machos alimentados com óleo de soja, óleo de canola e óleo de canola + vitamina E, aos 43 dias de idade

\begin{tabular}{lcccccc}
\multirow{2}{*}{ Tratamentos } & \multicolumn{7}{c}{ Variáveis analisadas } \\
\cline { 2 - 7 } & RC (\%) & RP (\%) & RPE (\%) & RD (\%) & RA (\%) & RGA (\%) \\
\hline Soja & $74,72 \mathrm{a}$ & $38,67 \mathrm{a}$ & $30,68 \mathrm{a}$ & $18,24 \mathrm{a}$ & $10,14 \mathrm{a}$ & $2,27 \mathrm{a}$ \\
Canola & $74,60 \mathrm{a}$ & $39,51 \mathrm{a}$ & $30,14 \mathrm{a}$ & $17,93 \mathrm{a}$ & $10,22 \mathrm{a}$ & $2,21 \mathrm{a}$ \\
Canola + Vit E & $74,71 \mathrm{a}$ & $39,49 \mathrm{a}$ & $29,85 \mathrm{a}$ & $18,33 \mathrm{a}$ & $9,96 \mathrm{a}$ & $2,37 \mathrm{a}$ \\
\hline CV (\%) & 1,61 & 5,15 & 4,47 & 6,86 & 4,96 & 23,07 \\
Valor P & 0,96 & 0,46 & 0,28 & 0,67 & 0,38 & 0,72 \\
\hline
\end{tabular}

Médias seguidas de letras diferentes, na coluna, diferem entre si pelo teste de Tukey $(\mathrm{P}<0,05)$. 
Com relação ao rendimento de carcaça, peito, perna, dorso, asas e gordura abdominal, não foram observadas diferenças entre os tratamentos experimentais (Tab. 4). Esses resultados corroboram os encontrados por Nobakht et al. (2012), que não observaram diferença significativa do rendimento de carcaça em frangos de corte alimentados com óleo de canola e vitamina E. Quanto à fonte de óleo, Nobakht et al. (2011), ao avaliarem o efeito de diferentes fontes e níveis de óleos vegetais, também não observaram diferenças no rendimento de carcaça e de cortes de frangos alimentados com óleo de soja ou canola. Esses resultados eram esperados, visto que não houve diferença no ganho de peso das aves.

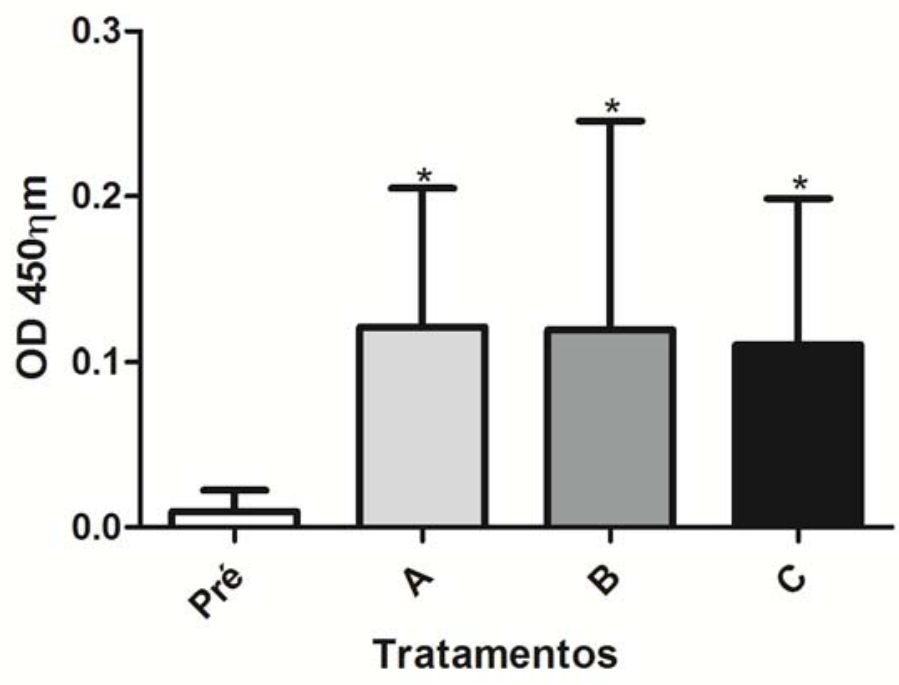

Figura 1. Produção de anticorpos IgY específicos anti-hemácia de carneiro. Ensaio imunoenzimático para determinação dos níveis de anticorpos IgYanti-hemácia de carneiro em amostras de sangue obtidas préimunização $\left(14^{\circ}\right.$ dia do experimento, pré) e após o $42^{\circ}$ dia do experimento de frangos de corte alimentados com óleo de soja (A), canola (B) e canola + vitamina E (C). Os dados estão expressos em média e desvio- padrão. *níveis de anticorpos significativamente maiores $(\mathrm{P}<0,05)$ do que os níveis préimunização, teste de Tukey.

Os resultados da avaliação da resposta imune humoral (Fig. 1) mostram que os animais responderam à inoculação do antígeno e que não há efeito dos tratamentos sobre a produção de anticorpos específicos $(\mathrm{P}>0,05)$. Resultados semelhantes foram obtidos por Pilevar et al. (2011), El-Bahra e Ahmed (2012) e Ahmed et al. (2013).

Os resultados obtidos nesta pesquisa podem ser explicados pela composição dos óleos, uma vez que o óleo de soja depara-se com 53,0\% de n-6 e $8,0 \%$ de n-3, enquanto o óleo de canola apresenta $22,0 \%$ de $n-6$ e 10,0\% de n-3 (Bertechini, 2012). Segundo Wall et al. (2010) e Calder (2006), ácidos graxos poli-insaturados n-3 melhoram a resposta imune e reduzem a inflamação em diferentes espécies, tais como frangos, ratos e peixes. Dessa forma, devido ao fato de o teor de n-3 nas diferentes fontes lipídicas utilizadas no experimento ser semelhante, estas não influenciaram na resposta imune das aves.

Em relação à vitamina $\mathrm{E}$, Leshchinski e Klasing (2001), ao utilizarem hemácias de carneiro como antígeno, encontraram maior produção de anticorpos com 50mg de vitamina $\mathrm{E} / \mathrm{kg}$ de ração do que com 0 e $200 \mathrm{mg}$ de vitamina $\mathrm{E} / \mathrm{kg}$. Os autores concluíram que a produção de anticorpos depende da natureza do antígeno e que níveis de 25 a $50 \mathrm{mg}$ de vitamina $\mathrm{E} / \mathrm{kg}$ seriam mais efetivos em desencadear resposta imune do que níveis elevados, que podem ter efeito citotóxico para os frangos (Thornton et al., 1995), de tal forma que o papel antioxidante da vitamina passa a ter efeito inverso, aumentando a formação de radicais livres no citosol e prejudicando o sistema imunológico das aves (Leshchinski e Klasing, 2001). 


\section{CONCLUSÃO}

Conclui-se que a utilização do óleo de canola ou do óleo de canola combinado com a vitamina $\mathrm{E}$ não afeta as características produtivas de carcaça, cortes e resposta imune humoral em frangos de corte em relação ao óleo de soja.

\section{REFERÊNCIAS}

AHMED, A.S.; EL-BAHR, S.M.; ALAZRAQUI, A.A. Effect of canola and olive oils on productive, immunological and some biochemical parameters of broiler chickens fed iso-caloric and high caloric diets. Int. J. Poult. Sci., v.12, p.726-734, 2013.

BAIÃO, N.C.; LARA, L.C.J. Oil and fat broiler nutrition. Braz. J. Poult. Sci., v.7, p.129-141, 2005.

BERTECHINI, A.G. Nutrição de monogástricos. Lavras: UFLA, 2012. 255p.

CALDER, P.C. n-3 Polyunsatured fatty acids, inflammation, and inflammatory diseases. Am. $J$. Clin. Nutr., v.83, p.1505-1519, 2006.

CARVALHO, G.B.; LOPES, J.B.; SILVA, S.R.G. et al. Desempenho, morfometria duodenal e histopatologia do fígado de frangos de corte alimentados com dietas contendo diferentes níveis de selênio orgânico em condições de estresse calórico. Rev. Bras. Saúde Prod. Anim., v.16, p.365-376, 2015.

CONTRERAS, C.C.; BERAQUET, N.J. Electrical stunning, hot boning, and quality of chicken breast. Poult. Sci., v.80, p.501-507, 2001.

CORTINAS, L.; BARROETA, A.; VILLAVERDE, C. et al. Influence of the dietary polyunsaturation level on chicken meat quality: lipid oxidation. Poult. Sci., v.84, p.48-55, 2005.

EL-ABASY, M.; MOTOBU, M.; NAKAMURA, $\mathrm{K}$. et al. Preventive and therapeutic effects of sugar cane extract on cyclophosphamide-induced immunosupression in chickens. Int. Immunopharmacol., v.4, p.983-990, 2004.

EL-BAHRA, S.M.; AHMED, A.S. Effect of vegetable oils on growth, lipid profile, and immunologic response in broiler in broiler chicken fed isoenergetic diet. Rev. Cient. Agric., v.12, p.201-206, 2012.
FASCINA, V.B. Valor energético, desempenho, lipídios séricos e composição corporal de frangos de corte recebendo óleo de soja e sebo bovino em diferentes combinações. 2007. 57f. Dissertação (Mestrado em Ciência Animal) Universidade Federal de Mato Grosso do Sul, Campo Grande, MS.

JUNQUEIRA, O.M.; ANDREOTTI, M.O.; ARAÚJO, F.L. et al. Valor energético de algumas fontes lipídicas determinado com frangos de corte. Rev. Bras. Zootec., v.34, p.2335-2339, 2005.

KIDD, M.T. Nutritional modulation of immune function in broilers. Poult. Sci., v.8, p.650-657, 2004.

KLASING, K.C. Nutritional modulation of resistance to infectious diseases. Poult. Sci., v.77, p.1119-1125, 1998.

KREUKNIET, M.B.; VAN DER ZIPJPP, A.J.; NIEUWLAND, M.G. Effects of route immunization, adjuvant and unrelated antigens on the humoral immune response in lines of chickens selected for antibody production against sheep erythrocytes. Vet. Immunol. Immunopathol., v.33, p.115-127, 1992.

LADICS, G.S. Use of SRBC antibody responses for immunotoxicity testing. Methods, v.41, p.919, 2007.

LEESON, S.; SUMMERS, J.D. Nutrition of the chicken. 4.ed. Ontario: University Books, 2001. 413p.

LESHICHINSKY, T.V.; KLASING, K.C. Relationship between the level of dietary vitamin $\mathrm{E}$ and the immune response of broiler chickens. Poult. Sci., v.80, p.1590-1599, 2001.

MENDES, A.A. Rendimento e qualidade da carcaça de frangos de cortes. In: CONFERÊNCIA APINCO DE CIÊNCIA E TECNOLOCIA AVÍCOLAS, 2001, Campinas. Anais...Campinas: FACTA, 2001. v.3, p.79-99.

MOLLAEI, A.; ABEDI, M.; BORDBAR, A.T. et al. The effects of using canola oil with vitamin E on performance and carcass traits of broilers. $J$. Biodivers. Environ. Sci., v.6, p.231-235, 2015.

NOBAKHT, A.; ARIYANA, A.; MAZLUM, F. Effect of different levels of canola oil with vitamin $\mathrm{E}$ on performance and carcass traits of broilers. Int. Res. J. Appl. Basic. Sci., v.3, p.1059-1064, 2012. 
NOBAKHT, A.; TABATBAEI, S.; KHODAEI, S. Effects of different sources and levels of vegetable oils on performance, carcass traits and accumulation of vitamin $\mathrm{E}$ in breast meat of broilers. Curr. Res. J. Biol. Sci., v.3, p.601-605, 2011.

PILEVAR, M.; ARSHAMI, J.; GOLIAN, A. et al. Effects of dietary n-6:n-3 ratio on immune and reproductive systems of pullet chicks. Poult. Sci., v.90, p.1758-1766, 2011.

PINTO, M.F.; LIMA, V.M.F.; RIBEIRO, S.C. et al. Fontes de óleo na dieta e sua influência no desempenho e na imunidade de frangos de corte. Pesqui. Vet. Bras., v.34, p.409-414, 2014.

POMPEU, M.A.; BAIÃO, N.C.; LARA, L.J.C. et al. Desempenho de frangos de corte alimentados com diferentes níveis de suplementação de vitamina E. Arq. Bras. Med. Vet. Zootec., v.67, p.506-510, 2015.

ROSTAGNO, H.S.; ALBINO, L.F.T.; DONZELE, J.L. et al. Tabelas brasileiras para aves e suínos: composição de alimentos e exigências nutricionais. 3.ed. Viçosa: UFV, 2011, 252p.
SANTOS, M.C. Efeito do enriquecimento da ração com ômega-3 e vitamina $E$ sobre a qualidade da carne de frango. 2014. 79f. Dissertação (Mestrado em Ciência de Alimentos) - Universidade Estadual de Londrina, Londrina, PR.

SIM, J.S.; TOY, B.; CRICK, D.C. Effect of dietary erucic acid on the utilization of oils of fats by growing chicks. Poult. Sci., v.64, p.21502154, 1985.

SMITH, M.O. Parts yield of broilers reared under cycling high temperatures. Poult. Sci., v.52, p.1146-1150, 1993.

THORNTON, D.E.; JONES, K.H.; JIANG, Z. et al. Antioxidant and cytotoxic tocopheryl quinones in normal and cancer cells. Free Radic. Biol. Med., v.18, p.963-976, 1995.

WALL, R.; ROSS, R.P.; FITZGERALD, G.F.; et al. Fatty acids from fish: the antiinflammatory potential of long chain omega 3 fatty acids. Nutr. Rev., v.68, p.280-289, 2010. 